\title{
Metal organic framework-coated gold nanorod as an on-demand drug delivery platform for chemo-photothermal cancer therapy
}

\author{
Junfeng Huang ${ }^{1,2+}$, Zhourui Xu ${ }^{3 \dagger}$, Yihang jiang ${ }^{3}$, Wing-cheung Law ${ }^{4}$, Biqin Dong ${ }^{5}$, Xierong Zeng ${ }^{1}$, Mingze Ma ${ }^{3}$,
} Gaixia $\mathrm{Xu}^{3^{*}}$, Jizhao Zou ${ }^{1^{*}}$ and Chengbin Yang ${ }^{3^{*}}$ (D)

\begin{abstract}
Chemo-photothermal therapy based on nanoparticles has emerged as a promising strategy for cancer treatment. However, its therapeutic efficacy and application potential are largely subjected to the uncontrollability and biotoxicity of functional nanoplatforms. Herein, a novel biocompatible and biodegradable metal organic framework (MOF), which was constructed by growing crystalline zeolitic imidazolate framework-8 on gold nanoroad (Au@ZIF-8), was designed and fabricated for efficient drug loading and controlled release. Owing to the large surface area and guestmatching pore size of ZIF-8, doxorubicin (DOX) was successfully loaded into the Au@ZIF-8 with a high drug loading efficiency of $37 \%$. Under NIR light or weakly acidic environment, the ZIF-8 layer was quickly degraded, which resulted in an on-demand drug release in tumour site. More importantly, under the irradiation of near infrared (NIR) laser, highly efficient cancer treatment was achieved in both in vitro cell experiment and in vivo tumour-bearing nude mice experiment due to the synergistic effect of photothermal (PTT) therapy and chemotherapy. In addition, the in vivo study revealed the good biocompatibility of Au@ZIF-8. This work robustly suggested that Au@ZIF-8 could be further explored as a drug delivery system for chemo-photothermal synergistic therapy.
\end{abstract}

Keywords: Metal organic framework, Gold nanorod, Photothermal therapy, Drug delivery, Biocompatible

\section{Background}

Cancer, as the most dreadful disease in the world, was responsible for nearly one-fifth of human death [1]. Owing to the great efforts contributed to the biomedical

\footnotetext{
*Correspondence: xugaixia@szu.edu.cn; zoujizhao@szu.edu.cn; cbyang@szu.edu.cn

${ }^{\dagger} J$ Junfeng Huang and Zhourui Xu contributed equally to this work

${ }^{1}$ Shenzhen Key Laboratory of Special Functional Materials \& Shenzhen

Engineering Laboratory for Advance Technology of Ceramics,

College of Materials Science and Engineering, Shenzhen University,

Shenzhen 518060, China

${ }^{3}$ Guangdong Key Laboratory for Biomedical Measurements

and Ultrasound Imaging, School of Biomedical Engineering, Shenzhen

University Health Science Center, Shenzhen 518060, China

Full list of author information is available at the end of the article
}

field in the past few decades, several cancer therapy approaches, such as chemotherapy [2], surgery [3], and radiotherapy [4], have been developed and used in clinical settings. As a major cancer therapeutic approach, the chemotherapy still faces many challenges in clinical practice, such as limited therapeutic efficacy, poor patient compliance and severe toxic-side effects [5]. In recent years, thanks to the encouraging progress of nanotechnology-based combined therapy [6], which integrated different components, such as drugs, targeting molecules, biodegradable polymers, into a single nanoplatform, has emerged as a potential solution to overcome the aforementioned hurdles. The synergism of various components not only contributed to a remarkable super-additive

(c) The Author(s) 2021. This article is licensed under a Creative Commons Attribution 4.0 International License, which permits use, sharing, adaptation, distribution and reproduction in any medium or format, as long as you give appropriate credit to the original author(s) and the source, provide a link to the Creative Commons licence, and indicate if changes were made. The images or other third party material in this article are included in the article's Creative Commons licence, unless indicated otherwise in a credit line to the material. If material is not included in the article's Creative Commons licence and your intended use is not permitted by statutory regulation or exceeds the permitted use, you will need to obtain permission directly from the copyright holder. To view a copy of this licence, visit http://creativeco mmons.org/licenses/by/4.0/. The Creative Commons Public Domain Dedication waiver (http://creativecommons.org/publicdomain/ zero/1.0/) applies to the data made available in this article, unless otherwise stated in a credit line to the data. 
therapeutic effect, but also significantly reduced the adverse effects [7-9]. Among diverse types of combinations, chemo-photothermal therapy has attracted special attentions for four major reasons: 1) hyperthermia could potentially sensitize tumor to chemo-drugs, 2) hyperthermia could enhance the cellular uptakes of drug carriers, 3) the localized drug release can be triggered by the photothermal effects [10], and 4) chemo-drug could efficiently interrupt the cell metabolism and soften the heat shock response upon hyperthermia [11]. All these features have enabled us to obtain satisfactory outcomes of cancer therapy with reduced side effects. Nevertheless, efficiency of chemo-photothermal therapy depends on the design and fabrication of nanoplatforms. Currently, core-shell nanostructures have become a gold standard due to the high flexibility to control the size, morphology, and individual function [12]. Hence, this work is focused on selecting safe and efficient functional components to fabricate a multifunctional nanoplatform for chemo-photothermal therapy.

With the continuous efforts in photothermal applications, various types of photothermal agents have been explored, including copper chalcogenide nanocrystals [13], nanocarbons [14], gold-based nanostructures [10, 15], black phosphorous[16], and organic dyes [17]. Among them, gold-based nanomaterials have more excellent performance for clinical translation owing to its promising photothermal responses and bio-inertness [18-20]. Up to now, four clinical trials (ClinicalTrials.gov identifier: NCT00848042, NCT01679470, NCT02680535 and NCT04240639) of photothermal therapy based on gold nanostructures have been endorsed by the National Institute of Health Clinical Center (U.S.A), suggesting that the great application potential of gold-based nanostructures. Currently, anisotropic gold nanorod (AuNR) with tunable optical properties has been demonstrated to be an ideal component for constructing core-shell nanoplatform for tumour therapy [21, 22]. When AuNR was used as a photothermal core, on-demand controllable drug release from the shell reservoir could be triggered by light excitation [23]. However, limited choices have been given for shell materials due to their low drug loading capability, toxic synthetic approaches, time-consuming synthesis, and high tendency in causing aggregation $[24,25]$. Therefore, in order to achieve the full potential of chemo-photothermal therapy, it is critical to choose biocompatible, biodegradable, and reliable shell materials.

Recently, metal-organic frameworks (MOFs), which composed of metal nodes and organic linkers, have emerged as promising materials for biomedical applications, such as drug delivery [26, 27], catalysis [28], molecular imaging [29], and biosensing [30], due to their exceptional large surface area and tunable inner cavity. Among them, zeolitic imidazolate framework-8 (ZIF8) with low-toxic $\mathrm{Zn}^{2+}$ and 2-methylimidazole (2-MIN) as the basic units, was recognized as a biocompatible and acid-responsive drug carrier [31]. In addition, the fabrication process requires no toxic additives with facile synthetic approach, which ensure the safety use and reliability of ZIF-8 nanostructures. Inspired by its unique properties, we envisaged a great opportunity to exploit the full potential of chemo-photothermal therapy by combining AuNR and ZIF-8 shell materials.

In this work, a multifunctional nanoplatform composed of AuNR, ZIF-8 and doxorubicin (DOX) were successfully designed and synthesized for chemo-photothermal synergistic therapy. Specifically, a core-shell formulation of Au@ZIF-8 was prepared by growing ZIF-8 material onto individual AuNR with the guidance of Polyvinylpyrrolidone (PVP) polymer. Ascribed to the remarkable surface area and guest-matching pore size of ZIF-8, an exceptional drug loading efficiency of 37\% were achieved in Au@ZIF-8/DOX formulation. Furthermore, the materials characteristics results demonstrated that the weak acidic condition and photothermal effect promoted degradation of ZIF-8 shell layer, which resulted in an on-demand controlled drug release. The Au@ZIF-8 showed a high photothermal effect upon NIR irradiation, and the generated heat not only directly killed cancer cells but also synergistically promoted the DOX release, which exhibited better performance for inhibiting cell viability than free DOX. Furthermore, in vivo therapeutic results confirmed that the synergistic chemo-photothermal by Au@ZIF-8/DOX + NIR achieved much higher treatment efficacy than photothermal therapy by Au@ ZIF-8 + NIR or chemotherapy by DOX only and even resulted in complete tumor elimination without obvious adverse effect. This work provides a novel design of $\mathrm{Au@}$ ZIF-8 nanoplatform for chemo- and photothermal therapy, which can lead to a synergistic therapeutic effect and hold great promise for future clinical translation.

\section{Materials and methods \\ Materials}

Cetyltrimethylammonium bromide (CTAB) was purchased from Sigma. Tetra-chloroauric acid $\left(\mathrm{HAuCl}_{4}\right)$, ascorbic acid $(99.0 \%)$, silver nitrate $\left(\mathrm{AgNO}_{3}\right)$, 2-methylimidazolate (2-MIM), Zinc nitrate hexahydrate, monosodium phosphate $\left(\mathrm{NaH}_{2} \mathrm{PO}_{4}\right)$, sodium hydrogen phosphate $\left(\mathrm{Na}_{2} \mathrm{HPO}_{4}\right)$, sodium borohydride $\left(\mathrm{NaBH}_{4}\right)$, polyvinyl pyrrolidone (PVP) were purchased from Aldrich. Doxorubicin Hydrocholoride (DOX) was purchased from Aladdin. 1,2-distearoyl-sn-glycero-3-phosphoethanolamine- $\mathrm{N}$-[methoxy(polyethylene glycol)-2000] (ammonium salt) (18:0 PEG2000PE) was purchased from Avanti. 
All the chemicals were used as received without further purification.

\section{The synthesis and characterization of nanocomplexes}

Transmission electronic microscopy (HR-TEM, JEOLF200; TEM, HTI-7700) was used to observe the morphology and size of Au@ZIF-8. Absorbance spectra of all the nanoparticle samples were recorded by using UVVis-NIR spectrophotometer (Tianjin Tuopu Instrument, TP-720). The crystal information of Au@ZIF-8 samples were measured by an X-ray Diffractometer (Rigaku Smartlab, JP). The photothermal performances of the samples were evaluated by an $808 \mathrm{~nm}$ laser (Changchun Leishi Photo-Electric Technology) and FLIR A300 infrared thermal imaging camera (FLIR Systems).

\section{The synthesis of AuNRs and Au@ZIF-8}

Gold nanorods (AuNRs) were synthesized in a seedmediated growth method. For the seed solution, $250 \mu \mathrm{L}$ of $0.01 \mathrm{M} \mathrm{HAuCl}_{4}$ was added to $10 \mathrm{~mL}$ of $0.1 \mathrm{M} \mathrm{CTAB}$ with rapid stirring. Ice-cold $600 \mu \mathrm{L}$ of $0.01 \mathrm{M} \mathrm{NaBH}_{4}$ solution was prepared and quickly dissolved into the mixture solution. The colour changed to dark brown, indicating the synthesis of gold seeds. The seed solution kept undisturbed for $2 \mathrm{~h}$ at $30{ }^{\circ} \mathrm{C}$ before use. For growth solution, $40 \mathrm{~mL}$ of $4 \mathrm{mM} \mathrm{CTAB}$ was mixed with $2 \mathrm{~mL}$ of $0.01 \mathrm{M} \mathrm{HAuCl}_{4}$, following with adding of $400 \mu \mathrm{L} 0.01 \mathrm{M}$ $\mathrm{AgNO}_{3}$ aqueous solution. The $\mathrm{pH}$ value of mixture was adjusted into 1 by addition of $1 \mathrm{M} \mathrm{HCl}$. Then $320 \mu \mathrm{L}$ of $0.10 \mathrm{M}$ ascorbic acid was added and the colour of the mixture became transparent after mild stirring. $400 \mu \mathrm{l}$ seed solution was added into growth solution and the mixture kept undisturbed in $4 \mathrm{~h}$ at $30^{\circ} \mathrm{C}$ for the growth of gold nanorods. The brown precipitations were collected with $12,000 \mathrm{rpm}$ centrifugation and dried for use in the next step.

Prior to grow ZIF-8 shell, a ligand exchange of CTABstabilized AuNR with PVP polymer is necessary. Briefly, $5 \mathrm{~g}$ PVP was dissolved into $100 \mathrm{~mL}$ DMF to form a homogeneous PVP/DMF solution. Next, the CTAB-stabilized AuNR was firstly precipitated by centrifugation and then resuspended in PVP/DMF solution with vigorous stirring for $2 \mathrm{~h}$. The AuNR@PVP was then collected by centrifugation. To grow ZIF-8 shell on AuNR, $2 \mathrm{~mL}$ of $22 \mathrm{mM}$ 2-MIM and $2 \mathrm{~mL}$ of $13 \mathrm{mM} \mathrm{Zn}\left(\mathrm{NO}_{3}\right)_{2}$ were added into $2 \mathrm{~mL}$ AuNR@ PVP solution under vigorous stirring $(2 \mathrm{~h})$ at room temperature. Then, Au@ZIF-8 was collected by centrifugation and washed with methanol twice. To endow water dispersity and biocompatibility on Au@ZIF-8, PEG2000PE was firstly added into the Au@ZIF-8 methanol suspension with 2:1 weight ratio, and then PEG2000PE-stabilized Au@ZIF-8 were added into water under ultrasonication.
Finally, the water dispersible Au@ZIF-8 were obtained by centrifugation.

\section{The evaluation of photothermal effect}

The photothermal response of Au@ZIF-8 was studied on a simple setup. Briefly, a plastic tube containing $200 \mathrm{uL}$ of sample dispersion with different concentrations were immobilized on an optical holder. $808 \mathrm{~nm}$ laser irradiation with $1 \mathrm{~W} \cdot \mathrm{cm}^{-2}$ power density was reflected by a $45^{\circ} \mathrm{mir}-$ ror to shed on nanorod samples in plastic tube. A thermal camera with an accuracy of $0.1{ }^{\circ} \mathrm{C}$ was operated in a perpendicular way to laser path for temperature detection. The heat conversion efficiency was calculated by using Eq. 1-4.

$$
\begin{aligned}
\eta & =\frac{\mathrm{hS}\left(T_{\text {max }}-T_{\text {ssur }}\right)-Q_{\text {dis }}}{\mathrm{I}\left(1-10^{-A_{808}}\right)} \\
\tau_{S} & =\frac{m_{D} C_{D}}{h S} \\
\mathrm{t} & =-\tau_{\mathrm{S}} \ln \theta \\
\theta & =\frac{T-T_{\text {surr }}}{T_{\text {max }}-T_{\text {surr }}}
\end{aligned}
$$

where " $\mathrm{h}$ " is the heat transfer coefficient, " $\mathrm{S}$ " is the surface area of the container, the value of "hS" can be obtained according to the cooling curve. $\mathrm{T}_{\max }$ is the steady-state temperature of photothermal agents while $T_{\text {ssur }}$ is the surrounding temperature. $Q_{\text {dis }}$ represents the energy absorbed by the container and solvent. "I" is the power of incident laser power $\left(1 \mathrm{~W} \cdot \mathrm{cm}^{-2}\right)$ while A808 is the absorbance of photothermal agents at $808 \mathrm{~nm}$.

Drug loading and controlled release of AuNR@ZIF-8 by $\mathrm{pH}$ response or NIR trigger DOX was used as anticancer drug for detailed drug loading and release tests. DOX was dissolved into DMF to form DOX solutions $(3.7 \mathrm{mM})$ and then mixed with $1 \mathrm{mg} \cdot \mathrm{mL}^{-1}$ AuNR@ZIF-8 DMF solution overnight, the mixture was denoted as the Au@ZIF-8/DOX. Various ratio of DOX and Au@ZIF-8 were performed to seek the ideal drug loading content and efficiency. The drug loading content and efficiency of DOX ( $\left.\mathrm{DLC}_{\mathrm{DOX}} \& \mathrm{DLE}_{\mathrm{DOX}}\right)$ were obtained according to the below equations respectively:

$$
\begin{aligned}
& D L C_{D O X}=\frac{W_{\text {loaded }}}{W_{\text {total }}}=\frac{W_{\text {original }}-W_{\text {residual }}}{W_{\text {loaded }}+W_{\text {nanoparticle }}} \\
& D L E_{D O X}=\frac{W_{\text {original }}-W_{\text {residual }}}{W_{\text {original }}}
\end{aligned}
$$


where $\mathrm{W}_{\text {loaded }}, \mathrm{W}_{\text {total }}$ and $\mathrm{W}_{\text {nanoparticles }}$ corresponded to the weight of loaded DOX, the weight of total micelles and the weight of DOX carriers (nanoparticles) respectively; And $\mathrm{W}_{\text {original }}$ and $\mathrm{W}_{\text {residual }}$ corresponded to the weight of DOX before and after mixing with AuNR@ ZIF-8 respectively. The residual weight of DOX was measured according to the standard curve for the DOX quantification. All data for DOX were adjusted by the standard curve in Additional file 1: Fig. S2. The in vitro drug release test was performed in PBS solutions. Equivalent Au@ZIF-8-DOX concentration (1 mg.mL ${ }^{-1}$ DOX) was used in different control group. There were four contrast groups in the tests: $\mathrm{pH}=7.4$ group without NIR irradiation, $\mathrm{pH}=7.4$ group with NIR irradiation, $\mathrm{pH}=5.8$ group without NIR irradiation and $\mathrm{pH}=5.8$ group under NIR irradiation. PBS solution was made up of $\mathrm{NaH}_{2} \mathrm{PO}_{4}$ and $\mathrm{Na}_{2} \mathrm{HPO}_{4}$ solution. During drug release tests, laser power, irradiation time and frequency were adjusted for optimal drug release. The amount of the released DOX was quantified by UV-Vis spectroscopy as the abovementioned method.

\section{In vitro cytotoxicity of Au@ZIF-8}

The cytotoxicity of Au@ZIF-8 was investigated by using HeLa cells and MCF-7 cells. The cells were seeded in 96-well plates at a density of 5000 cells/well and grown in $5 \% \mathrm{CO}^{2}$ at $37{ }^{\circ} \mathrm{C}$. Then, Au@ZIF-8 with diverse concentrations were supplemented into the medium and the cells were incubated for another $24 \mathrm{~h} .10 \mu \mathrm{L}$ of 3-[4,5-dimethylthiazol-2-yl]-2,5-diphenyltetrazolium bromide (MTT) solution was further added into each well and incubated for another $4 \mathrm{~h}$. The supernatant in each well was discarded and supplemented with $150 \mu \mathrm{L}$ of dimethyl sulfoxide (DMSO). The plate was examined using a microplate reader (Bio-tek, Epoch-2) at the wavelength of $490 \mathrm{~nm}$ to evaluate the cell viability. To evaluate the PTT efficacy of Au@ZIF-8, diverse concentrations of Au@ZIF-8 were firstly added into the medium of each well and incubated for $4 \mathrm{~h}$. After replacement with fresh medium, the cell samples were exposed under $808 \mathrm{~nm}$ laser of $1.0 \mathrm{~W} \cdot \mathrm{cm}^{-2}$ for $7 \mathrm{~min}$. After that, the cells were further cultured for $24 \mathrm{~h}$. The MTT process was carried out as mentioned to assess the cell viability.

\section{Live and dead cell staining assay}

To evaluate and visualize the PTT effect on Au@ZIF8-treated cell samples, Live/Dead Cell Double Staining Kit was applied on cell samples after photothermal treatment. Briefly, $2 \mathrm{uL}$ working solution of Calcein-AM and PI were added into each well of 6-well plate. After incubation of $15 \mathrm{~min}$ and replacement with fresh culture medium, the cell samples were imaged by fluorescent microscopy. Calcein-AM is a cell-permeable and non-fluorescent compound, however, becomes fluorescent once enters into metabolically active cells. PI is a fluorescent nucleic acid dye that can permeate only the damaged cell membrane.

\section{Hemolysis assay}

The impact of the surface chemistry of Au@ZIF-8 on red blood cells (RBCs) of mice and the influence of the protein corona interaction on this process was investigated by the standard haemolysis assays. A volume of $4 \mathrm{~mL}$ of blood was added to the anticoagulant tube. The blood was mixed gently and centrifuged at 3,500 rpm for $15 \mathrm{~min}$. The supernatant was removed, and the precipitated RBCs were washed three times by re-suspending them in a $1 \times$ PBS solution ( $\mathrm{pH} 7.4)$. The final working suspension utilized for the haemolysis assay consisted of $5 \%(\mathrm{v} / \mathrm{v})$ of RCBs in a PBS solution. To evaluate the haemolytic effect, Au@ZIF-8 with diverse concentrations were incubated with RBCs ( $200 \mu \mathrm{L}$ of a $5 \%$ suspension) for $2 \mathrm{~h}$ through a static method after gentle homogenization. The final volume of the haemolysis assay was set to be $1.0 \mathrm{~mL}$. Then, the samples were centrifugated and $100 \mu \mathrm{L}$ of supernatants were extracted for quantifying the haemoglobin by measuring the absorbance at $540 \mathrm{~nm}$. De-ionized (DI) water and PBS solution were used as positive control and negative control, respectively. The percentage of haemolysis was calculated based on Eq. 7 .

$$
\text { Hemolysis rate }(\%)=\frac{\mathrm{ABS}_{\text {sample }}-\mathrm{ABS}_{\text {neg-contl }}}{\mathrm{ABS}_{\text {posit-contl }}-\mathrm{ABS}_{\text {neg-contl }}} \times 100 \%
$$

\section{In Vivo photothermal therapy}

The tumour-suppressive effects of Au@ZIF-8 with or without $808 \mathrm{~nm}$ laser irradiation were evaluated on nude mice ( $20 \mathrm{~g}$ ), which were purchased from Guangdong Medical Laboratory Animal Center. All animal experiments conform to the guidelines of the University Animal Care and Use Committee. The right axilla of each mouse was injected with MCF-7 cells subcutaneously to establish tumours. The tumours were allowed to grow for fourteen days to reach a size of around $200 \mathrm{~mm}^{3}$. Then, the MCF-7 tumour-bearing BALB/c mice were randomly divided into 8 groups $(\mathrm{N}=4)$, which were intravenously injected with PBS, DOX, Au@ZIF-8, and DOX-loaded Au@ZIF-8, with or without laser irradiation. The injected dose of DOX solution (in PBS) was $3.6 \mathrm{mg} \cdot \mathrm{kg}^{-1}$. The injected dose of Au@ZIF-8 suspension (in PBS) was $10 \mathrm{mg} \cdot \mathrm{kg}^{-1}$ body weight in total. The photothermal treatment was performed on day 1 . The body weight and tumour volumes were recorded every two days. The tumour volume was calculated using the following 
equation: Tumour Volume $(\mathrm{V})=\pi \times$ length $\times$ width $^{2} / 8$ $\times 4 / 3$. Moreover, the tumour tissues in each group were harvested from mice $24 \mathrm{~h}$ after the first photothermal treatment. The tumour tissues were further fixed in paraformaldehyde and stained with hematoxylin and eosin $(\mathrm{H} \& \mathrm{E})$ staining assay.

\section{In vivo biocompatibility assay}

The in vivo toxicity of Au@ZIF-8 was carried out by using BALB/c mice as animal models. PBS was injected as the negative control. Au@ZIF-8 with three dose schemes $\left(1,10\right.$, and $\left.20 \mathrm{mg} \cdot \mathrm{kg}^{-1}\right)$ were applied on BALB/c mice $(n=4)$. The body weight of mice in each group were recorded for every two days. On day 15, all mice were sacrificed. Their major organs (heart, liver, spleen, lung, and kidney) were retrieved to analyse the organic coefficient and perform H\&E staining. Their blood samples were taken to characterize the blood routine test and blood biochemical test.

\section{Statistical analysis}

Data were represented as means \pm SD. The representative experimental data were indicated as mean \pm standard deviation (SD). The statistical was examined by Student's $t$-test when two groups were compared. Differences were considered statistically significant when $P$-values lower than 0.05 .

\section{Results and discussion \\ Fabrication and characterization of Au@ZIF-8 nanocomplex}

The fabrication process of drug loaded Au@ZIF-8 and its therapeutic mechanism are illustrated in Scheme 1. Firstly, AuNRs were prepared according to the classical seed-mediated method with cetyltrimethylammonium bromide (CTAB) as the capping agents [32]. By further exchanging the ligands with PVP polymer, crystallized ZIF-8 layer was gradually growing on AuNR by chelation reaction between $\mathrm{Zn}^{2+}$ and 2-MIN in methanol. Then, PEG2000PE was applied as capping agent to endow

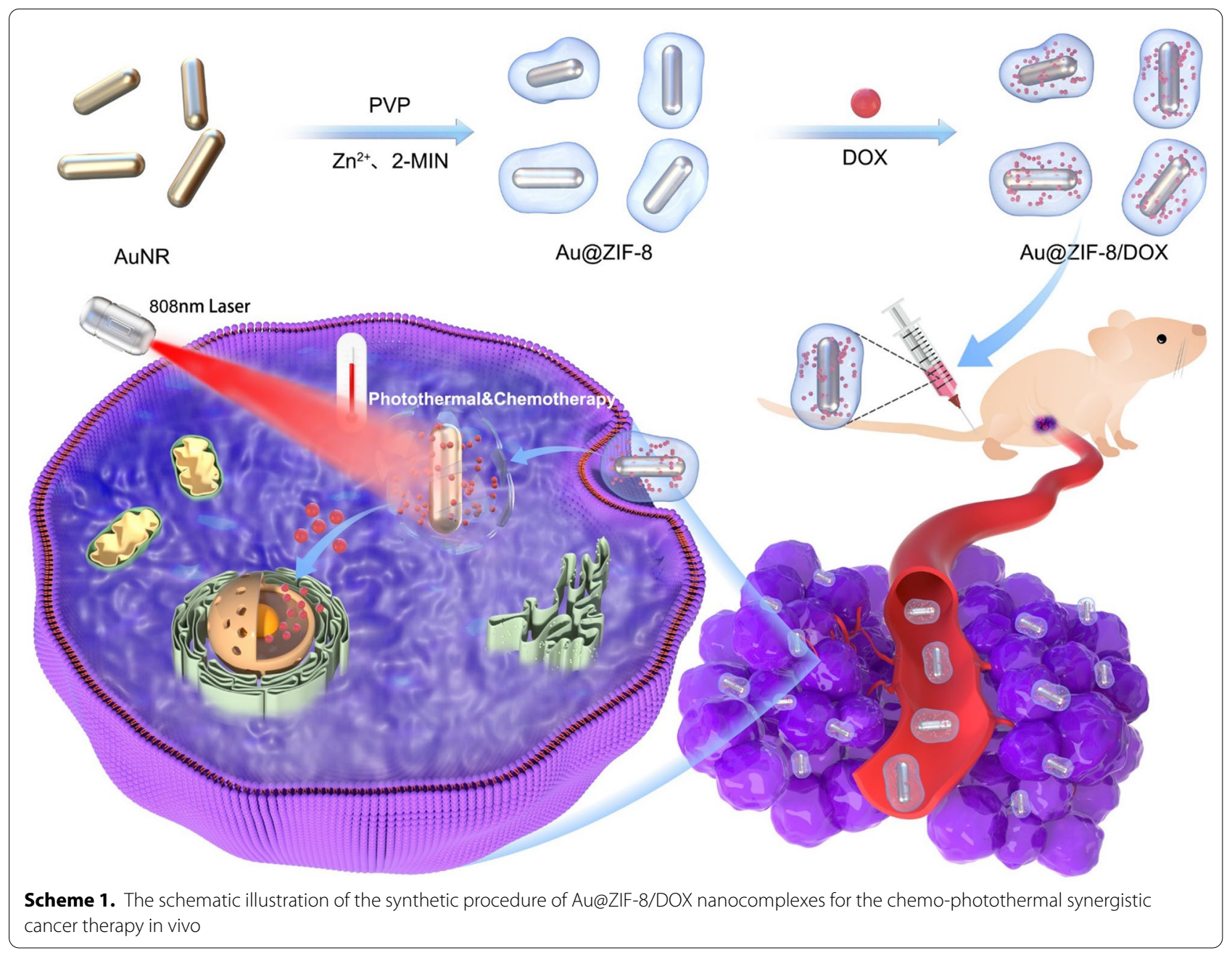


Au@ZIF-8 with water solubility and biocompatibility. Ascribed to the facile preparation process and enhanced water dispersity, highly monodispersed nanoparticles with round ellipsoid shape were obtained (Fig. 1a). This could be explained by the homogeneous-growing of shell layer. The inner structure of Au@ZIF-8 was examined by TEM microscopy. The core-shell conformation was clearly presented with AuNR as core and ZIF-8 as shell (Fig. 1b). As shown in Fig. 1c, the aspect ratio of AuNR core is about 3.9 and thickness of MOF shell layer is about $\sim 25 \mathrm{~nm}$. The composition of Au@ZIF-8 was further confirmed by energy-dispersive X-ray (EDX) elemental mapping. Figure $1 \mathrm{~d}$ shows a rod-shaped $\mathrm{Au}$ element map in the core and homogeneous distribution of nitrogen $(\mathrm{N})$ and zinc $(\mathrm{Zn})$ element in ellipsoid shape, which further confirmed the core-shell formulation of Au@ZIF-8. XRD spectrum also evidenced that ZIF-8 was successfully crystallized and capped around AuNR core. The signal pattern of Au@ZIF-8 well matches with face-centred cubic structure of gold and ZIF-8 (Fig. 1e), which as corresponding to the results implied by TEM images and EDX mapping. The absorption spectrum of Au@ZIF-8 was shown in Fig. 1f. Compared to AuNR, the absorption peak of Au@ZIF-8 slightly redshifted from 790 to $808 \mathrm{~nm}$. This phenomenon could be explained by the difference of refractive index around AuNR, thereby altering the frequency of localized surface plasmon resonance [33]. In addition, the absorption spectra of Au@ZIF-8 with different concentrations was measured, in which a distinct absorption peak at $\sim 800 \mathrm{~nm}$ was observed (Fig. 1g). Therefore, the photothermal effect of the prepared Au@ZIF-8 was set at 808 nm wavelength in the following experiments.

\section{Photothermal effect and on-demand drug release}

The photothermal responses of Au@ZIF-8 were evaluated under the irradiation of $808 \mathrm{~nm}$ laser $\left(1 \mathrm{~W} \cdot \mathrm{cm}^{-2}\right)$. The result revealed that the temperature elevation of Au@ZIF-8 has positive correlation with the concentration of samples and the irradiation time (Fig. 2a, b). Typically, the temperature of Au@ZIF-8 suspension at high concentration of $200 \mathrm{ppm}$ increased quickly, from $23{ }^{\circ} \mathrm{C}$ to $54{ }^{\circ} \mathrm{C}$, within $5 \mathrm{~min}$ and was finally stabilized at $54{ }^{\circ} \mathrm{C}$. However, the temperature variation of deionized (DI) water irradiated by NIR laser was only $2.5^{\circ} \mathrm{C}$, under the same experimental condition (Fig. 2b), indicating
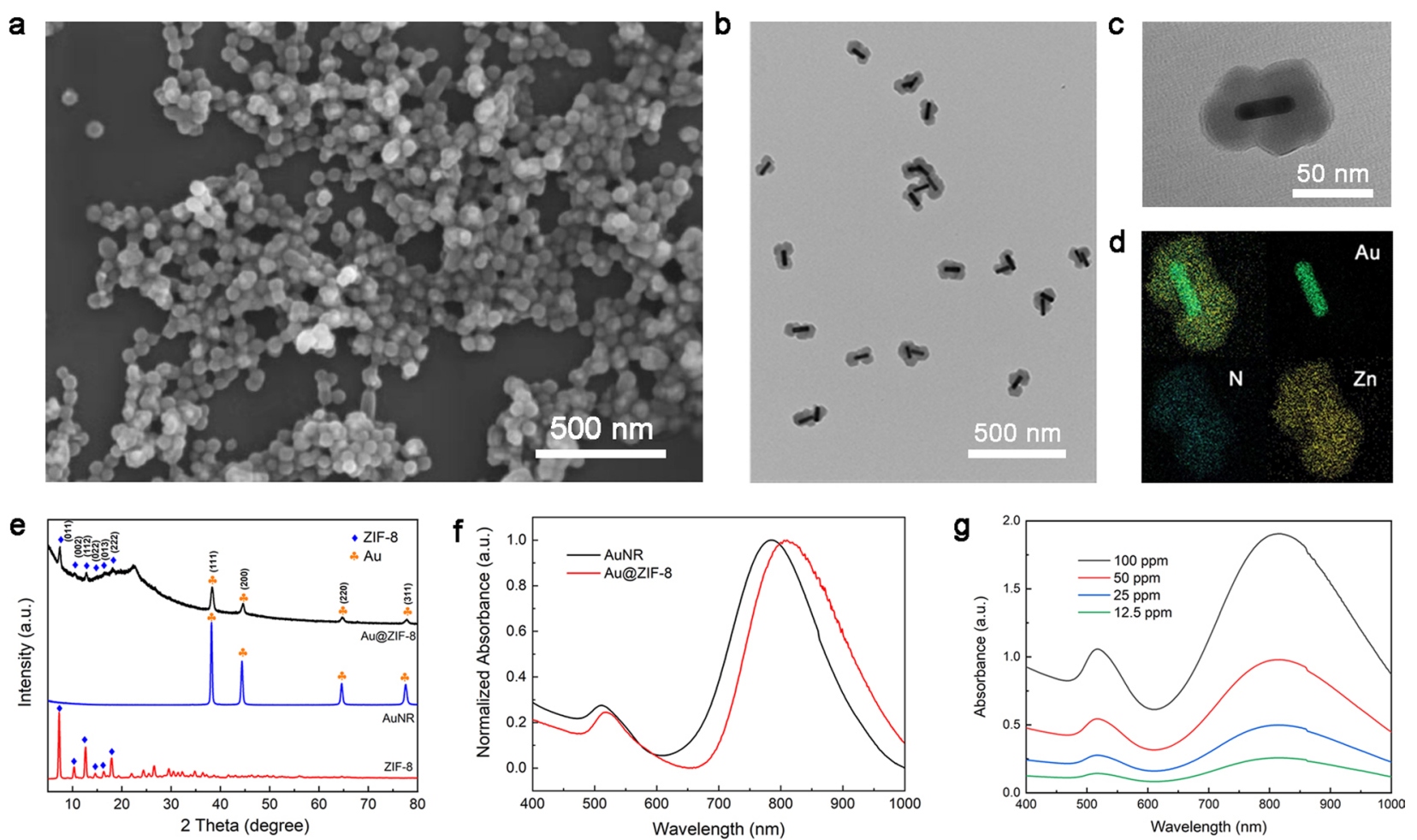

Fig. 1 The characterization of Au@ZIF-8 nanocomplexes. a The morphology and distribution of Au@ZIF-8 indicated by SEM image. The inner structure, detailed diameter and composition are presented by $\mathbf{b}$ low magnified TEM image, $\mathbf{c}$ high magnified TEM image, and $\mathbf{d}$ EDX-elemental mapping. e The crystal information was examined byXRD patterns. fThe absorption spectra of Au@ZIF-8 and AuNR were measured by spectrophotometer. $\mathbf{g}$ The absorption spectra of different concentrations of Au@ZIF-8 


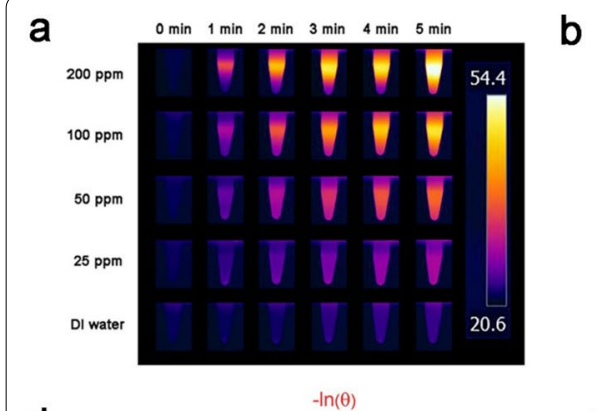

d

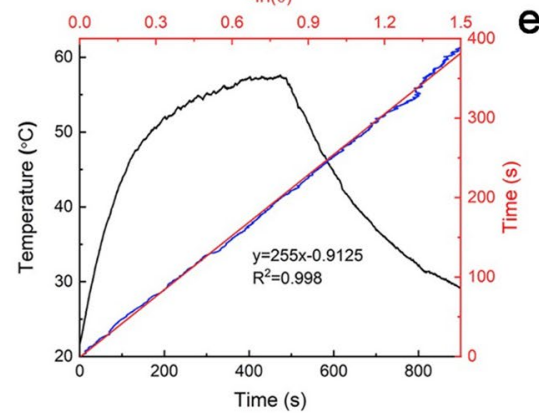

b
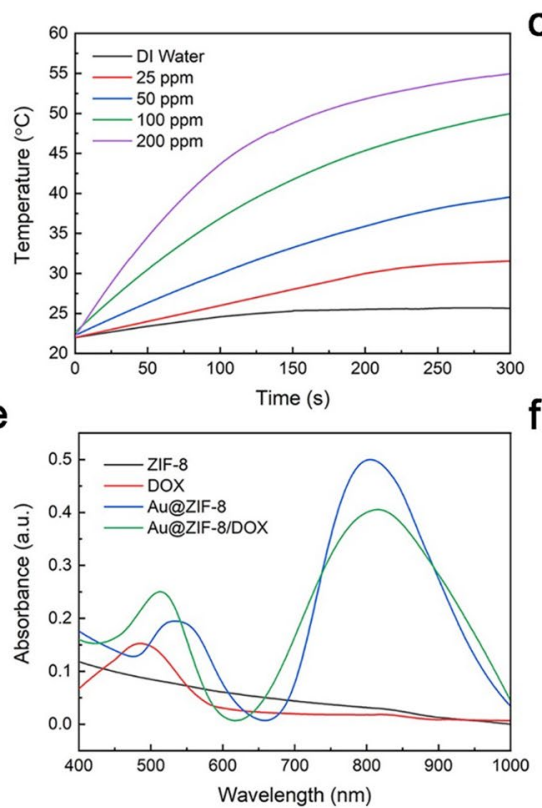

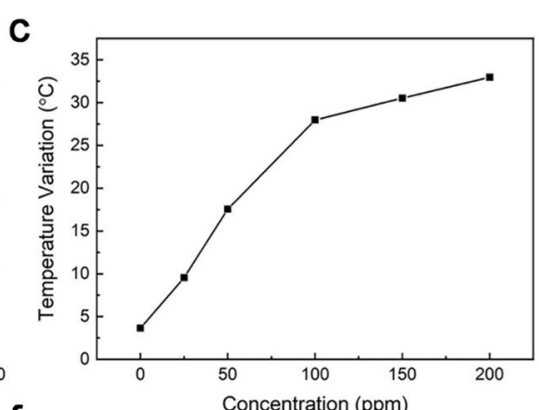

f

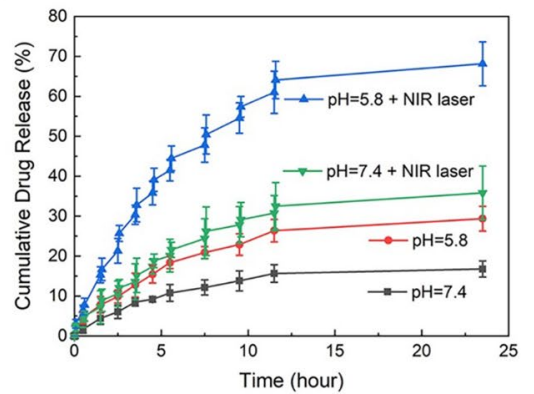

Fig. 2 The photothermal responses and controlled drug release of Au@ZIF-8. a The temperature gradience of Au@ZIF-8 in diverse concentration under laser irradiation for $5 \mathrm{~min}$. b The temperature elevation curve and $\mathbf{c}$ the final temperature of Au@ZIF-8 at different concentrations irradiated by $808 \mathrm{~nm}$ NIR laser for $5 \mathrm{~min}$. $\mathbf{d}$ The photothermal and natural cooling curve of Au@ZIF-8. eThe absorption spectra of different formulations. $\mathbf{f}$ The cumulative drug releasing curve of Au@ZIF-8/DOX under different conditions. (Laser: $808 \mathrm{~nm}, 1 \mathrm{~W} \cdot \mathrm{cm}^{-2}$ )

that the increase of temperature was due to the photothermal conversion of AuNRs. It is noted that the rate of increase of temperature was not linearly related to the concentration of Au@ZIF-8. The temperature of Au@ZIF-8 increased as $\sim 0.25{ }^{\circ} \mathrm{C} \cdot \mathrm{ppm}^{-1}$ below $100 \mathrm{ppm}$ while dropped to $0.05{ }^{\circ} \mathrm{C} \cdot \mathrm{ppm}^{-1}$ with higher concentration (Fig. 2c). The sensitive light-to-heat conversion was ascribed to the promising photothermal heating conversion efficiency (HCE) of AuNR. Based on Eqs. 1, 2, 3 and 4 in the experimental section and Fig. $2 \mathrm{~d}$, the HCE of Au@ZIF-8 was calculated to be 22\%, which was comparable to AuNR alone and implies that ZIF-8 coating does not affect the photothermal effect of AuNR. Moreover, the heat energy producing from Au@ZIF-8 can be used to facilitate the rapid release of drug payloads in the pores of outer shell. Drug loading content and loading efficiency of DOX were assessed in aqueous solution ( $\mathrm{pH}$ 7.4) at room temperature. As shown in Additional file 1: Fig. S1, the colour of mixed solution changed into mild purple after DOX loading. The detailed results were collected from absorbance spectra and calculated based on Eqs. 5 and 6 in experimental section. DOX standard curve was measured prior to ensure the accuracy of results (Additional file 1: Fig. S2). The drug loading content of Au@ZIF-8 was stable around 36\% in different molar ratio and reached the highest at $37.32 \%$ with molar ratio of 3 (Additional file 1: Table S1). The drug loading efficiency showed a decreased trend when the molar ratio increased. The highest efficiency was $92.8 \%$ when the molar ratio was 1 . Therefore, the ratio of $\mathrm{Au@}$ ZIF-8 and DOX in the coming tests were fixed as 1:1. It can be deduced that the excellent drug loading efficiency of Au@ZIF-8 is attributed to the high surface area after the encapsulation of MOF shell. The absorption spectra of different formulations (AuNR, ZIF-8, Au@ZIF-8, DOX and Au@ZIF-8/DOX) were shown in Fig. 2e. Generally, ZIF-8 demonstrated weak absorption between 400 and $1000 \mathrm{~nm}$, suggesting that the influence of MOF on the optical absorption of AuNR is minimal. It may also provide additional explanation for the comparable HCE between AuNR and Au@ZIF-8. After loading DOX, the maximum absorption peak of Au@ZIF-8 mildly shifts from 528 to $512 \mathrm{~nm}$.

Then, the drug release behavior was investigated in different $\mathrm{pH}$ environmental conditions (Fig. 2f). Obviously, the DOX release rate under acidic condition $(\mathrm{pH}$ 5.8) was much higher than that under neutral condition. Within $24 \mathrm{~h}$, over $26 \%$ of DOX was released at $\mathrm{pH} 5.8$, while only $13 \%$ of DOX was released for $\mathrm{pH} 7.4$, which might be attributed to the degradation of MOF under acidic condition. TEM images clearly showed that the shell of Au@ZIF-8 underwent gradual decomposition under acid condition. Naked AuNRs were observed due to structural collapse and disappears of outside MOF 
shell. (Additional file 1: Fig. S3a). Moreover, the impact of temperature evaluation on the drug release was also evaluated. The results indicated that laser irradiation significantly enhanced DOX release. Upon the NIR irradiation, the release rate (68\%) of DOX at acidic condition was $33 \%$ faster than that at $\mathrm{pH} 7.4$, which confirms that the photothermal effect of Au@ZIF-8 can accelerate the drug release. The generated heat energy from photothermal effect further promoted the instability of ZIF-8 under acid condition (Additional file 1: Fig. S3b), thereby improving the release rate of DOX. The engineering of MOF shell structure onto AuNRs can also efficiently avoid the premature leakage of DOX under physiological conditions, reducing the adverse effect of chemotherapeutic drugs. Therefore, this photo and $\mathrm{pH}$ dual-responsive drug delivery manner of Au@ZIF-8/ DOX was greatly desired for the controlled release of DOX at acidic tumour environment, thus improving its therapeutic effect.

\section{Intracellular internalization and in vitro chemo-photothermal therapy}

The cellular uptake of Au@ZIF-8 was visualized under confocal laser scanning microscopy (CLSM). MCF-7 cells were incubated with DOX-loaded Au@ZIF-8 (Au@ZIF-8/DOX) for $4 \mathrm{~h}$, followed by staining with LysoTracker green, which was a commercial fluorescent dye used for indicating the location of lysosomes. The red fluorescence of DOX and green fluorescence of LysoTracker green are well overlapped, implying that endocytosis process was the major route to internalize Au@ZIF-8 (Additional file 1: Fig. S4). Additionally, it was noted that the DOX fluorescence was majorly distributed outside the nucleus. After treated with PBS, DOX, Au@ZIF-8, and Au@ZIF-8/DOX, the MCF-7 cells were observed under CLSM (Fig. 3a). It can be seen that blue fluorescence which represents cell nucleus can be clearly visualized in all samples. The red fluorescence of DOX can only be observed in DOX- and Au@ZIF-8/DOXtreated cells. In addition, DOX-treated cells have a well overlapped fluorescence profile of red and blue while the red fluorescence in Au@ZIF-8/DOX treated-cells largely distributed around blue fluorescence. This phenomenon should attribute to the delayed DOX release behaviour of Au@ZIF-8 when compared with the free DOX. After the cell internalization, the photothermal effect of Au@ ZIF-8 on anti-cancer effect was investigated, MCF-7 cells incubated with different formulations were irradiated by $808 \mathrm{~nm}$ laser (Fig. 3b). Next, the therapeutic efficacy of Au@ZIF-8 were further studied by MTT assay on MCF-7 cells. Briefly, PBS, DOX, Au@ZIF-8, and Au@ZIF-8/ DOX were incubated respectively with MCF-7 cells. The concentrations of Au@ZIF-8 used in this experiment were set as $(1,2.5,5,10,25$, and $50 \mathrm{ppm}$, based on the $\mathrm{Au}$ contents), and the DOX concentrations were about 37\% of Au@ZIF-8. The viabilities of MCF-7 cells in different treatments groups were assessed by MTT assay after $24 \mathrm{~h}$ of incubation (Fig. 3c). The results indicated the group treated with Au@ZIF-8 only exhibited negligible cytotoxicity without laser irradiation. MCF-7 cells treated with DOX shared similar cytotoxicity in both laser and non-laser treatment due to the absence of photothermal response. The cytotoxic effect of combination group (Au@ZIF-8/DOX + laser irradiation) drastically increased to $82 \%$ at the highest concentration of $50 \mathrm{ppm}$, which was much better than single photothermal or chemotherapy group. On the other hand, the synergistic anti-cancer effect in combination group depends on concentration of Au@ZIF-8/DOX. The treatment efficacy was further evaluated by live/dead staining method using Calcein-AM/propidium iodide (PI) dye after $4 \mathrm{~h}$ treatment. Without dead cells were observed in PBS- and DOX-treated cells, and all cells display green fluorescence with well-spread morphology (Fig. 3d). In contrast, obvious cell death regions were observed in Au@ZIF-8 treated and Au@ZIF-8/DOX-treated cells, as evidenced by the increased red spots, suggesting the promising potential of photothermal therapy of Au@ZIF8. Besides, no remarkable necrotic cell was observed for cells exposed to NIR laser alone, indicating the inappreciable side effect of applied laser. Taken together, those results demonstrated that Au@ZIF-8/DOX can realize superior anti-cancer effect under NIR laser irradiation, which was possibly benefited from the well-coordinated chemo-photothermal therapy.

\section{In vivo chemo-photothermal therapy}

MCF-7 tumour-bearing nude mice were used to evaluate the in vivo therapeutic efficacy of Au@ZIF-8/DOX nanocomplex. The nanoparticle suspension (in PBS) was intravenously injected into the mice prior to perform the photothermal treatment. The in vivo photothermal effect of Au@ZIF-8/DOX nanocomplex was visualized by thermal imaging system (Fig. 4a). The temperature of intratumor area of mouse treated with Au@ZIF-8/DOX nanocomplex increased rapidly to $47{ }^{\circ} \mathrm{C}$ under the laser irradiation (Fig. 4b), which suggesting the efficient accumulation of nanoparticles in tumour site. The enhanced accumulation may be ascribed to the passive targeting phenomenon, governed by enhanced permeability and retention effect (EPR). In contrast, the negative control group, with mice treated with PBS buffer only, demonstrated limited temperature increment at tumour site. Then, the tumour inhibition rate of Au@ZIF-8/DOX nanocomplex was systematically evaluated. The body weight of mice in each group were recorded in every two 


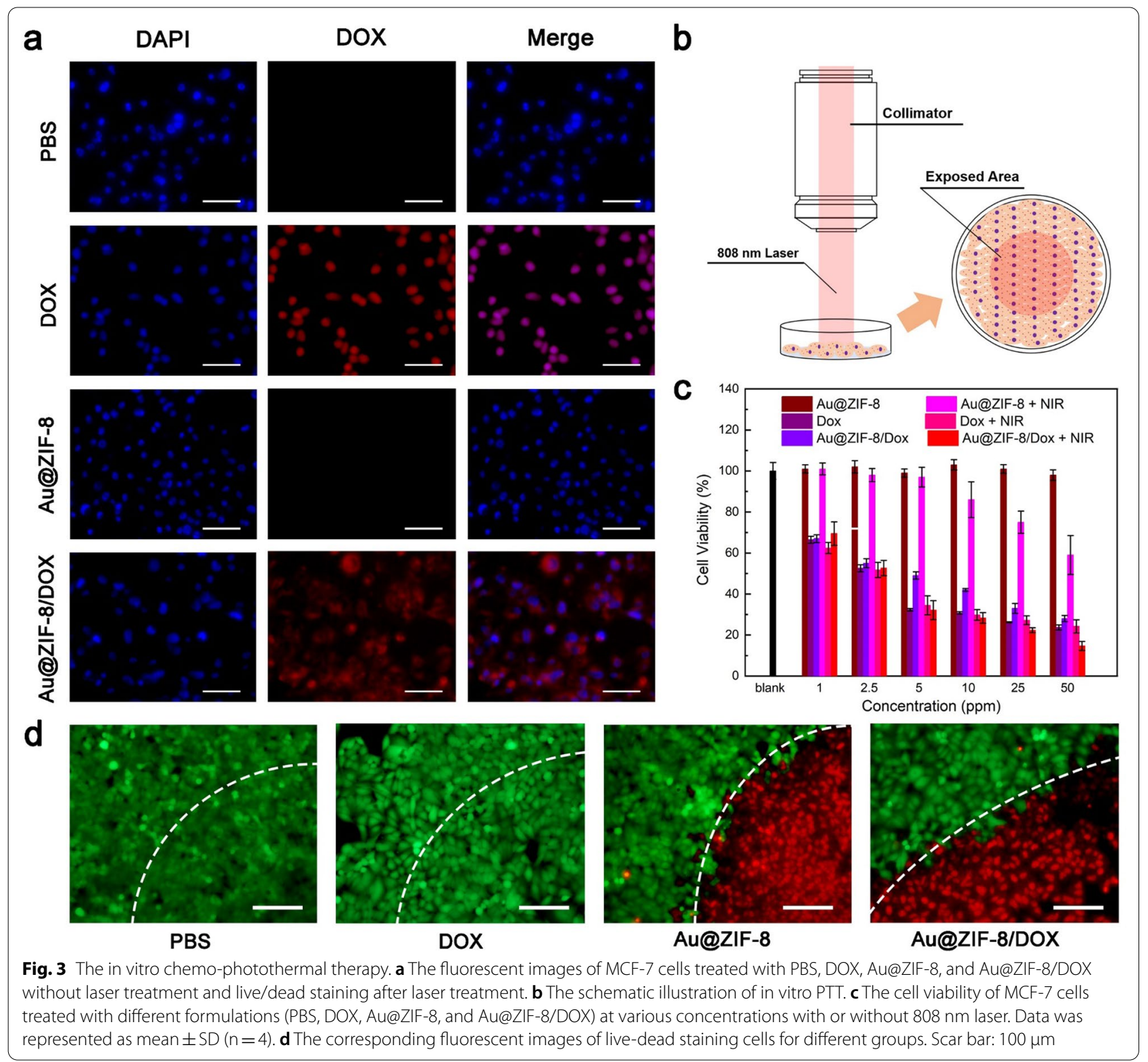

days within 17 days. As shown in Fig. 4c, mice treated with PBS (with or without NIR laser) exhibit gradually growing body weight in the first 13 days, followed by weight stable in the rest of days. Mice treated with DOX gradually loss weight in the late stages of the treatment due to the side effect of chemotherapy. For mice treated with Au@ZIF-8/DOX and laser irradiation, the body weight of mice decreased slightly in the first half time and gradually recovered to its original state by the second half time. These results indicated that Au@ZIF-8, as drug carrier for DOX, can efficiently reduce the toxicity of DOX and potentially, exerting the therapeutic effects of DOX in a controlled manner.
To acquire more insights in cancer treatment, the tumour volume of all mice has been calculated and recorded throughout the assessment time. As shown in Fig. 4d, e, tumours were grown aggressively within 17 days without the intervention of DOX and PTT respectively (groups: PBS, PBS+NIR, and Au@ZIF8). In contrast, the tumour volume in groups (DOX, DOX + NIR, and Au@ZIF-8/DOX) were strictly restrained in their original state. Importantly, the combination group (Au@ZIF-8/DOX + laser irradiation) exhibited best inhibition effect on tumour growth than other experimental groups. It was encouraging that half of tumour were completely eliminated in the combination 


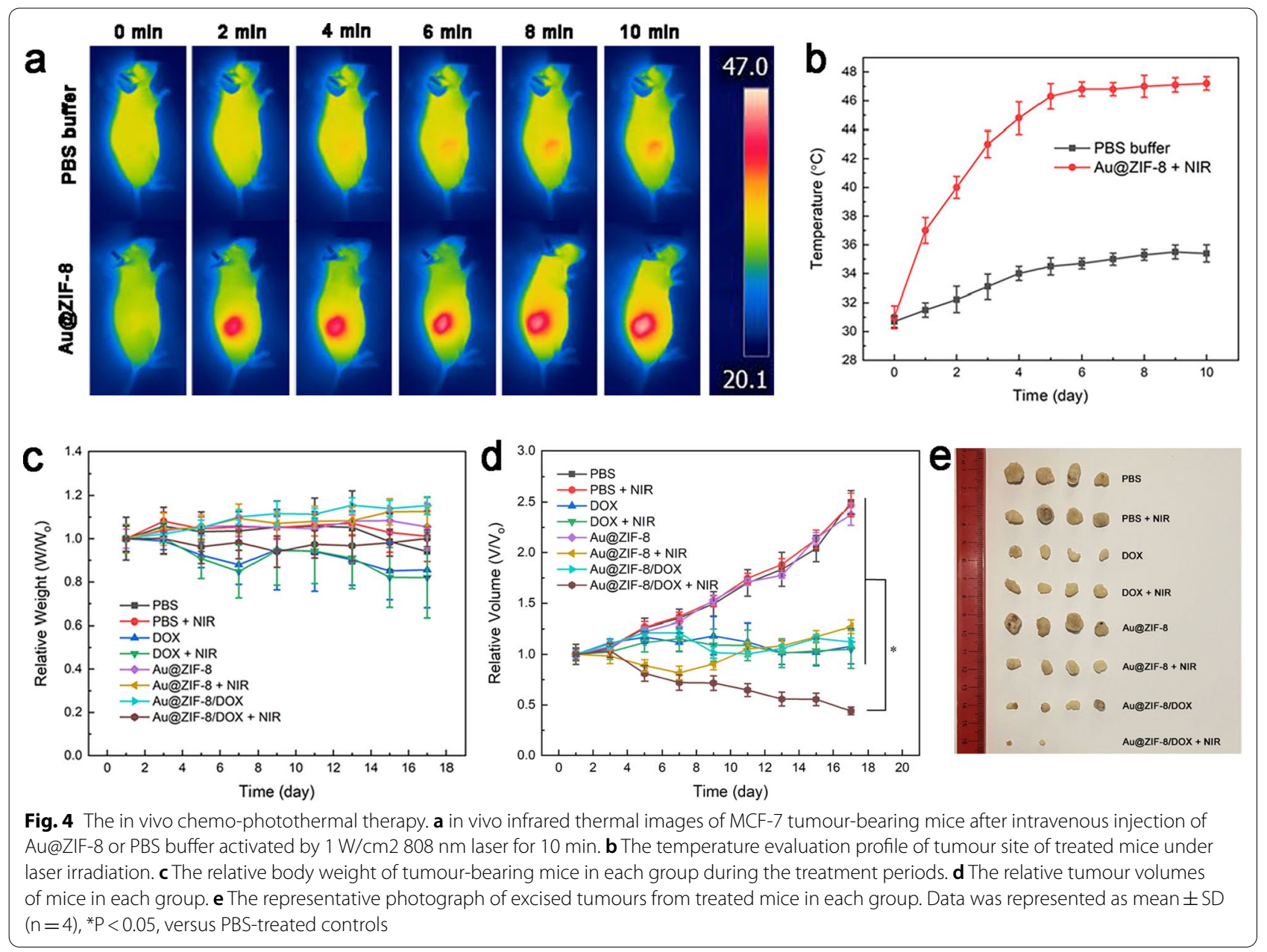

groups. Although the photothermal therapy alone (Au@ ZIF-8+ laser irradiation) also can reduce the tumour growth at the beginning of treatment, the tumour relapse and continuous to growth in the following days. Comparatively, the tumor growth of combination group was completely inhibited during the studied period. On the basis of those results, it can be concluded that Au@ ZIF-8/DOX-based synergistic treatment offers more efficient approach than the single-modal therapy.

\section{The cytotoxicity evaluation of Au@ZIF-8 nanocomplexes}

The intracellular cytotoxicity of Au@ZIF-8 nanocomplex at diverse concentrations were studied on cancer cell lines and normal cell lines, including HeLa (cervical cancer cell line), MCF-7 (breast cancer cell line) cell, NIH3T3 cell (normal embryonic fibroblast cell line), and HUVECs cells (human umbilical vein endothelial cells). After co-incubating $24 \mathrm{~h}$, the cell survival rates were all over $90 \%$ even at high concentration (up to 400 ppm) of Au@ZIF-8 (Additional file 1: Fig. S5), clearly indicating the excellent biocompatibility of Au@
ZIF-8. Such negligible cytotoxicity could be attributed to the encapsulation of PEG2000PE polymer, which has been well recognized as modification materials for improving the hydrophily and biocompatibility of nanoparticle [34]. The haemolysis analysis on Au@ ZIF-8 was further conducted to evaluate the hemocompatibility in blood samples. Briefly, a wide range of concentration of Au@ZIF-8 nanoparticles, which covering from 0-200 ppm, was incubated with diluted RBC suspension (in PBS) for $4 \mathrm{~h}$. DI water and PBS buffer were taken as positive and negative controls. The typical absorption peak of haemoglobin at $541 \mathrm{~nm}$ was not found for the samples at various concentrations of Au@ZIF-8 when compared with positive control. The haemolytic percentage of Au@ZIF-8 was quantitatively analysed based on the absorbance value. The haemolysis percentages of Au@ZIF-8 were all less than 4\% in the pre-designed concentrations (Additional file 1: Fig. 5a), suggesting the negligible haemolytic activity of Au@ZIF-8, which would benefit to in vivo long-term circulation in blood. 


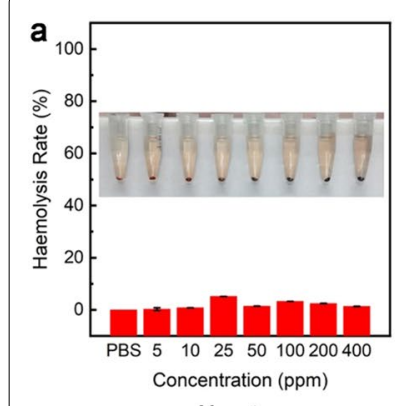

Heart
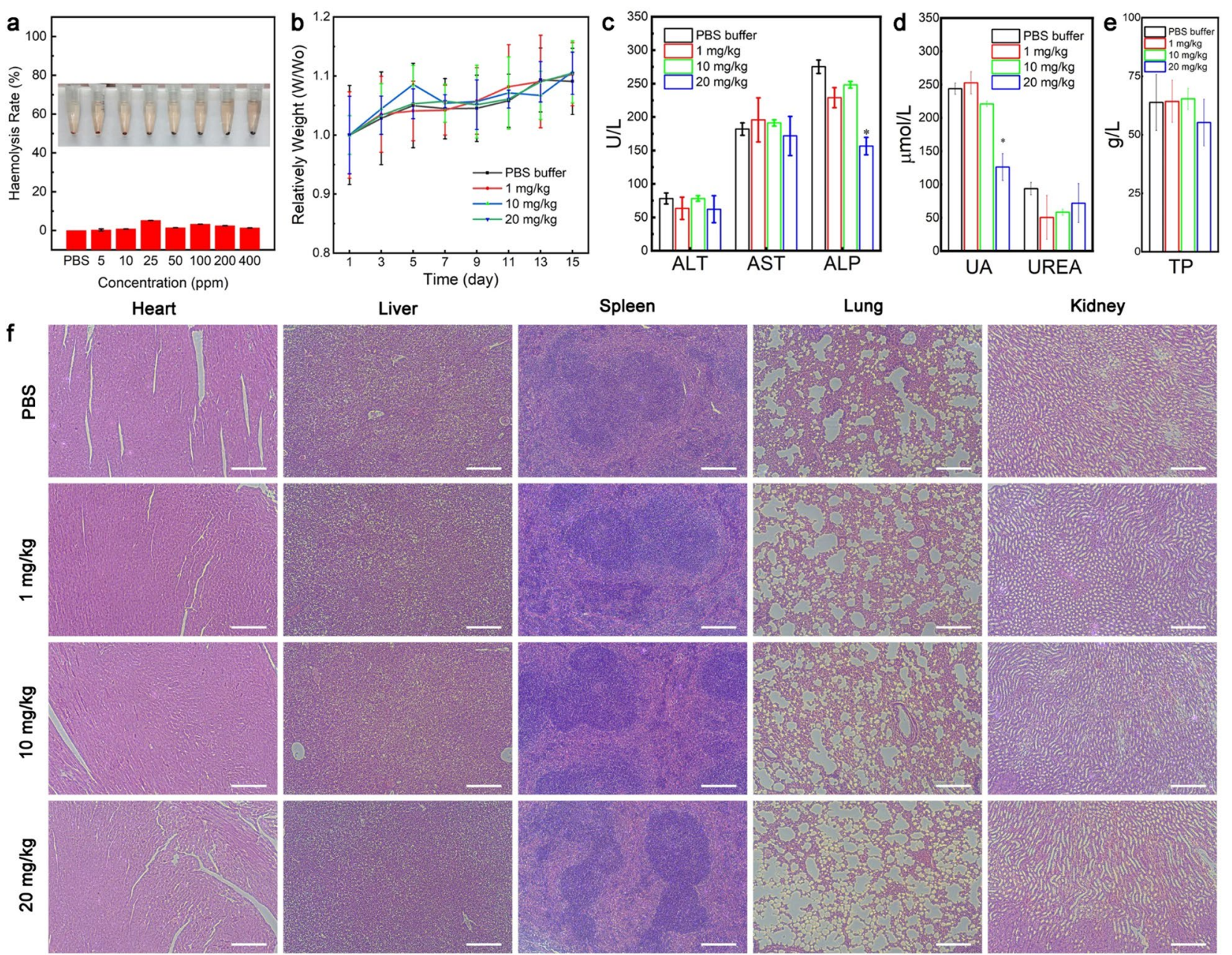

Liver

Spleen
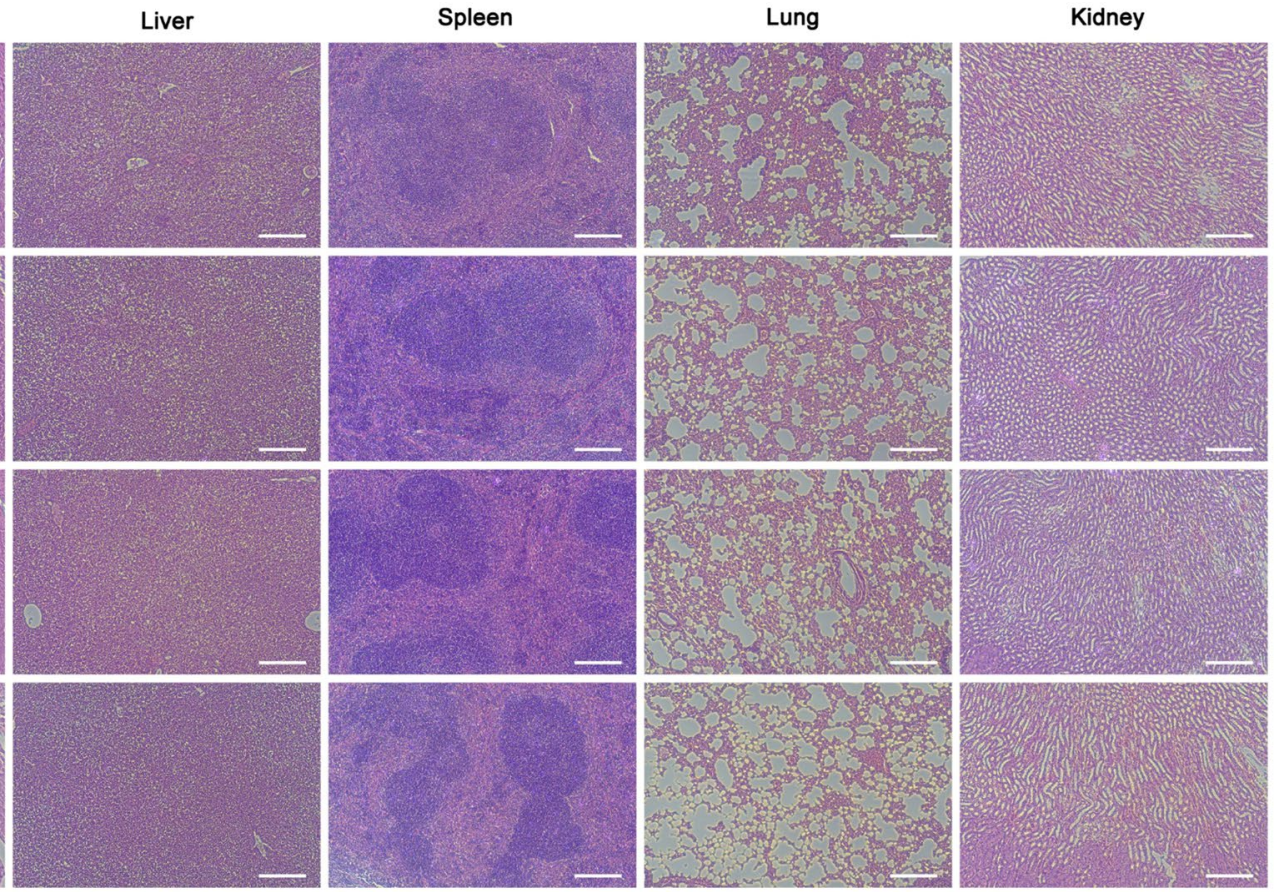

Fig.5 In vitro and in vivo toxicity evaluation of Au@ZIF-8 nanoparticles. a The haemolysis result of Au@ZIF-8 with different concentrations. b The body weight changes of mice with different treatments over 15 days. The blood biochemistry analysis for $\mathbf{c}$ liver functions, $\mathbf{d}$ kidney functions and $\mathbf{e}$ blood fat levels at day 15 after treatments. uric acid, UA; blood urea nitrogen, UREA; alanine transaminase, ALT; aspartate transaminase, AST; alkaline phosphatase, ALP; total protein, TP; triglyceride. $\mathbf{f H a e m a t o x y l i n}$ and eosin (H\&E) staining images of major organs (heart, liver, spleen, lung, and kidney) of mice treated with different doses of Au@ZIF-8 nanoparticles. Data was represented as mean \pm SD ( $n=4$ ). Scar bar: $200 \mu m$

\section{Biocompatible assessment of Au@ZIF-8 nanocomplexes}

Furthermore, the in vivo biosafety of Au@ZIF-8 nanocomplex were systematically evaluated by blood analysis and histological evaluation. The $\mathrm{BALB} / \mathrm{c}$ mice were randomly divided into four groups and intravenously injected with PBS and Au@ZIF-8 of three dose schemes $\left(1,10,20 \mathrm{mg} \cdot \mathrm{kg}^{-1}\right)$. Overall, all groups of mice exhibited normal change profile on body weight with slightly increase within 17 days (Fig. 5a). The blood typical blood routine index and biochemical indicators of all treated mice were maintained within the normal range (Fig. 5b, e). Especially, kidney/liver indexes of Au@ZIF-8 treated groups displayed no abnormality as compared to control group, thereby suggesting that the prepared Au@ZIF-8 do not induce deleterious effects. In general, the liver and kidney were the mainly affected organs involved in nanotoxicology due to the nonspecific aggregation. The biocompatibility of Au@ZIF-8 may be due to the rapid clearance effect of reticulo-endothelial system. Meanwhile, it can reasonably conclude that the biodegradability of Au@ZIF-8 would also benefit to its elimination from organs, thus reducing the risk of long-term retention. Further, The H\&E-stained tissue section indicated that the major organs (heart, liver, spleen, lung, and kidney) of Au@ ZIF-8 nanoparticles treated mice have normal cell morphology and no abnormal pathological changes even at the highest dosage of $20 \mathrm{mg} \cdot \mathrm{kg}^{-1}$ (Fig. 5f). These results 
well implied the good biocompatibility and negligible toxicity of Au@ZIF-8 in vivo, indicating the promising potential for future clinical translation.

\section{Conclusions}

In summary, a novel design of a multifunctional nanoplatform, composed of AuNR, ZIF-8 and DOX, was successfully fabricated via facile method. Attributed to the unique porous structure of ZIF-8 shell, a remarkable DOX loading efficiency of $\sim 37 \%$ were achieved. Under weak acidic condition and photothermal effects, a controlled drug release phenomenon was observed, which gave rise to a multiple stimuli-responsive cancer therapy. Under the irradiation of $808 \mathrm{~nm}$ laser, highly efficient chemo-photothermal therapy was realized both in vitro and in vivo experiments. Moreover, the high biocompatibility of Au@ZIF-8 was confirmed by in vivo study. Considering the synergistic therapeutic effect and excellent biosafety, Au@ZIF-8 has great potential as a promising nanoplatform for cancer therapy in future.

\section{Supplementary Information}

The online version contains supplementary material available at https://doi. org/10.1186/s12951-021-00961-X.

Additional file 1: Figure S1. Images of the aqueous solutions for DOX, Au@ZIF-8 and Au@ZIF-8/DOX respectively, under natural day light. Figure S2. Standard curve of DOX in different concentrations. Table S1. Drug loading content and loading efficiency of Au@ZIF-8/DOX in different weight ratios. Figure S3. TEM images for decomposed Au@ZIF-8 (scale bar: $200 \mathrm{~nm}$ ) (a) after $808 \mathrm{~nm}$ laser irradiation in 10 minutes, (b) in $\mathrm{Ph}=5.8$ weak acidic aqueous condition for 24 hours. Figure S4. The confocal images of MCF-7 cells after incubated with Au@ZIF-8/DOX for 4 hours, Figure S5. Cytotoxic evaluation of Au@ZIF-8 on HeLa (cervical cancer cell line), MCF-7 (breast cancer cell line) cell, NIH3T3 cell (normal embryonic fibroblast cell line), and HUVECs cells (human umbilical vein endothelial cells).

\section{Acknowledgements}

We thank Instrument Analysis Centre of Shenzhen University for the assistance with imaging analysis.

\section{Authors' contributions}

CY, JZ and GX provided the conceptual framework for the study. JH, ZX, and YJ designed and performed experiments and discussed the results. $W L, B D, X Z$, and $\mathrm{MM}$ helped with data analysis and manuscript revision. JH, ZX, and $\mathrm{CY}$ COwrote the paper. All authors read and approved the final manuscript.

\section{Funding}

This work was supported by the National Natural Science Foundation of China (31871442, 81801859), Natural Science Foundation of Guangdong Province (2019A1515012163, 2020A1515011018, 2021A1515012159), Guangdong Medical Science and Technology Research Funding(A2019359), the Research Grants Council of the Hong Kong Special Administrative Region, China (PolyU 15200518 and 15208720), Shenzhen Basic Research Program (JCYJ20190808141611189, JCYJ20180305125254860), Start-up Grant from Shenzhen University (2019136), and University Stable Support Research Funding of Shenzhen (20200813153346001)
Availability of data and materials

All data generated or analysed during this study are included in this published article.

\section{Declarations}

Ethics approval and consent to participate

Animal experiment is in accordance with the regulations of the Animal Ethical and Welfare Committee of Shenzhen University (AEWC-SZU).

\section{Consent for publication}

All authors agree to be published.

\section{Competing interests}

The authors declare no conflict of interest.

\section{Author details}

${ }^{1}$ Shenzhen Key Laboratory of Special Functional Materials \& Shenzhen Engineering Laboratory for Advance Technology of Ceramics, College of Materials Science and Engineering, Shenzhen University, Shenzhen 518060, China. ${ }^{2}$ Key Laboratory of Optoelectronic Devices and Systems of Ministry of Education and Guangdong Province, College of Physics and Optoelectronic Engineering, Shenzhen University, Shenzhen 518060, China. ${ }^{3}$ Guangdong Key Laboratory for Biomedical Measurements and Ultrasound Imaging, School of Biomedical Engineering, Shenzhen University Health Science Center, Shenzhen 518060, China. ${ }^{4}$ Department of Industrial and Systems Engineering, The Hong Kong Polytechnic University, Hong Kong 999077, China. ${ }^{5}$ Guangdong Provincial Key Laboratory of Durability for Marine Civil Engineering, College of Civil and Transportation Engineering, Shenzhen University, Shenzhen 518060, China.

Received: 11 June 2021 Accepted: 11 July 2021

Published online: 19 July 2021

\section{References}

1. Siegel RL, Miller KD, Fuchs HE, Jemal A. Cancer statistics, 2021. CA Cancer J Clin. 2021;71:7-33.

2. Sparano JA, Gray RJ, Makower DF, Pritchard Kl, Albain KS, Hayes DF, Geyer CE, Dees EC, Goetz MP, Olson JA, et al. Adjuvant chemotherapy guided by a 21-gene expression assay in Breast Cancer. N Engl J Med. 2018;379:111-21.

3. Strobel O, Neoptolemos J, Jäger D, Büchler MW. Optimizing the outcomes of pancreatic cancer surgery. Nat Rev Clin Oncol. 2019;16:11-26.

4. Taylor C, Correa C, Duane FK, Aznar MC, Anderson SJ, Bergh J, Dodwell $D$, Ewertz M, Gray R, Jagsi R, et al. Estimating the risks of breast cancer radiotherapy: evidence from modern radiation doses to the lungs and heart and from previous randomized trials. J Clin Oncol. 2017;35:1641-9.

5. Vasan N, Baselga J, Hyman DM. A view on drug resistance in cancer. Nature. 2019;575:299-309.

6. Gu Z, Zhu S, Yan L, Zhao F, Zhao Y. Graphene-based smart platforms for combined cancer therapy. Adv Mater. 2019;31:1800662.

7. Yang CB, Chan KK, Xu GX, Yin MJ, Lin GM, Wang XM, Lin WJ, Birowosuto MD, Zeng SW, Ogi T, et al. Biodegradable polymer-coated multifunctional graphene quantum dots for light-triggered synergetic therapy of pancreatic cancer. Acs Appl Mater Interfaces. 2019;11:2768-81.

8. Yang C, Chan KK, Lin W-J, Soehartono AM, Lin G, Toh H, Yoon HS, Chen C-K, Yong K-T. Biodegradable nanocarriers for small interfering ribonucleic acid (siRNA) co-delivery strategy increase the chemosensitivity of pancreatic cancer cells to gemcitabine. Nano Res. 2017;10:3049-67.

9. Wang YC, Wu B, Yang CB, Liu MX, Sum TC, Yong KT. Synthesis and characterization of $\mathrm{Mn}$ : ZnSe/ZnS/ZnMnS sandwiched QDs for multimodal imaging and theranostic applications. Small. 2016;12:534-46.

10. Yin F, Yang C, Wang Q, Zeng S, Hu R, Lin G, Tian J, Hu S, Lan RF, Yoon HS, et al. A light-driven therapy of pancreatic adenocarcinoma using gold nanorods-based nanocarriers for co-delivery of doxorubicin and siRNA. Theranostics. 2015:5:818-33.

11. Fisher JW, Sarkar S, Buchanan CF, Szot CS, Whitney J, Hatcher HC, Torti SV, Rylander CG, Rylander MN. Photothermal response of human and murine 
cancer cells to multiwalled carbon nanotubes after laser irradiation. Cancer Res. 2010;70:9855-64.

12. Huang J, Xu Y, Xiao H, Xiao Z, Guo Y, Cheng D, Shuai X. Core-shell distinct nanodrug showing on-demand sequential drug release to act on multiple cell types for synergistic anticancer therapy. ACS Nano. 2019;13:7036-49.

13. Xu Z, Rao N, Tang C-Y, Cheng C-H, Law W-C. Aqueous phase synthesis of $\mathrm{Cu}(2-\mathrm{x}) \mathrm{S}$ nanostructures and their photothermal generation study. ACS Omega. 2019:4:14655-62.

14. Panwar N, Soehartono AM, Chan KK, Zeng S, Xu G, Qu J, Coquet P, Yong K-T, Chen X. Nanocarbons for biology and medicine: sensing, imaging, and drug delivery. Chem Rev. 2019;119:9559-656.

15. Gong BL, Shen YB, Li HY, Li XJ, Huan X, Zhou JH, Chen YQ, Wu J, Li W. Thermo-responsive polymer encapsulated gold nanorods for single continuous wave laser-induced photodynamic/photothermal tumour therapy. J Nanobiotechnol. 2021;19:14.

16. Xie Z, Peng M, Lu R, Meng X, Liang W, Li Z, Qiu M, Zhang B, Nie G, Xie N, et al. Black phosphorus-based photothermal therapy with aCD47-mediated immune checkpoint blockade for enhanced cancer immunotherapy. Light Sci Appl. 2020;9:161

17. Wang H, Chang J, Shi M, Pan W, Li N, Tang B. A dual-targeted organic photothermal agent for enhanced photothermal therapy. Angew Chem Int Ed. 2019;58:1057-61.

18. Ali MRK, Wu Y, El-Sayed MA. Gold-nanoparticle-assisted plasmonic photothermal therapy advances toward clinical application. J Physl Chem C 2019;123:15375-93.

19. Rastinehad AR, Anastos H, Wajswol E, Winoker JS, Sfakianos JP, Doppalapudi SK, Carrick MR, Knauer CJ, Taouli B, Lewis SC, et al. Gold nanoshelllocalized photothermal ablation of prostate tumors in a clinical pilot device study. P Natl Acad Sci. 2019;116:18590-6.

20. Zhou W, Hu K, Kwee S, Tang L, Wang Z, Xia J, Li X. Gold nanoparticle aggregation-induced quantitative photothermal biosensing using a thermometer: a simple and universal biosensing platform. Anal Chem. 2020;92:2739-47.

21. Liu J, Liang H, Li M, Luo Z, Zhang J, Guo X, Cai K. Tumor acidity activating multifunctional nanoplatform for NIR-mediated multiple enhanced photodynamic and photothermal tumor therapy. Biomaterials. 2018;157:107-24.

22. Ren M, Zhou J, Song Z, Mei H, Zhou M, Fu ZF, Han H, Zhao L. Aptamer and RVG functionalized gold nanorods for targeted photothermal therapy of neurotropic virus infection in the mouse brain. Chem Eng J. 2021;411:128557.

23. Li Y, Jin J, Wang D, Lv J, Hou K, Liu Y, Chen C, Tang Z. Coordinationresponsive drug release inside gold nanorod@metal-organic framework core-shell nanostructures for near-infrared-induced synergistic chemophotothermal therapy. Nano Res. 2018;11:3294-305.

24. Jin $N$, Zhang $Q$, Yang $M$, Yang M. Detoxification and functionalization of gold nanorods with organic polymers and their applications in cancer photothermal therapy. Microsc Res Tech. 2019;82:670-9.

25. Encinas-Basurto D, Ibarra J, Juarez J, Pardo A, Barbosa S, Taboada P, Valdez MA. Hybrid folic acid-conjugated gold nanorods-loaded human serum albumin nanoparticles for simultaneous photothermal and chemotherapeutic therapy. Materials Sci Eng C. 2018;91:669-78.

26. Cai W, Wang JQ, Chu CC, Chen W, Wu CS, Liu G. Metal organic frameworkbased stimuli-responsive systems for drug delivery. Adv Sci. 2019;6:20.

27. Xiong F, Qin ZN, Chen HM, Lan QM, Wang ZT, Lan NH, Yang Y, Zheng L, Zhao JM, Kai D. pH-responsive and hyaluronic acid-functionalized metal-organic frameworks for therapy of osteoarthritis. J Nanobiotechnol. 2020;18:14

28. Li D, Xu HQ, Jiao L, Jiang HL. Metal-organic frameworks for catalysis: State of the art, challenges, and opportunities. Energy Chem. 2019;1:100005.

29. Zhou J, Tian G, Zeng L, Song X, Bian X-W. Nanoscaled metal-organic frameworks for biosensing, imaging, and cancer therapy. Adv Healthcare Mater. 2018;7:1800022.

30. Sun Z, Wang L, Wu S, Pan Y, Dong Y, Zhu S, Yang J, Yin Y, Li G. An electrochemical biosensor designed by using Zr-based metal-organic frameworks for the detection of glioblastoma-derived exosomes with practical application. Anal Chem. 2020;92:3819-26.

31. Li J, Zhu D, Ma W, Yang Y, Wang G, Wu X, Wang K, Chen Y, Wang F, Liu W, Yuan Y. Rapid synthesis of a Bi@ZIF-8 composite nanomaterial as a near-infrared-II (NIR-II) photothermal agent for the low-temperature photothermal therapy of hepatocellular carcinoma. Nanoscale. 2020;12:17064-73.

32. Gole A, Murphy CJ. Seed-mediated synthesis of gold nanorods: role of the size and nature of the seed. Chem Mater. 2004;16:3633-40.

33. Mejía-Salazar JR, Oliveira ON. Plasmonic biosensing. Chem Rev. 2018;1 18:10617-25.

34. Piffoux M, Silva AKA, Wilhelm C, Gazeau F, Tareste D. Modification of extracellular vesicles by fusion with liposomes for the design of personalized biogenic drug delivery systems. ACS Nano. 2018;12:6830-42.

\section{Publisher's Note}

Springer Nature remains neutral with regard to jurisdictional claims in published maps and institutional affiliations.
Ready to submit your research? Choose BMC and benefit from:

- fast, convenient online submission

- thorough peer review by experienced researchers in your field

- rapid publication on acceptance

- support for research data, including large and complex data types

- gold Open Access which fosters wider collaboration and increased citations

- maximum visibility for your research: over $100 \mathrm{M}$ website views per year

At BMC, research is always in progress.

Learn more biomedcentral.com/submissions 